\title{
Small and medium sized wine producers dealing with business to business e-commerce: Towards a relational model for enhancing value (co-) creation
}

\author{
Andrea Saba ${ }^{1}$, Silvia Rolandi ${ }^{1}$, and Marco Pilloni ${ }^{2}$ \\ ${ }^{1}$ Scuola Superiore di Studi Universitari e di Perfezionamento Sant'Anna, Pisa, Italy \\ ${ }^{2}$ Studio Psicologia del Lavoro, Cagliari, Italy
}

\begin{abstract}
The internet has produced a forward-looking shift in the way we communicate, think and run economic activities around the globe. The revolution in Information and Communication Technology (ICT) has generated an innovating process in the agri-food sector that is far from being unwind. The wine industry is a case in point. Indeed, the industry has attempted to address the multifaceted challenges posed by electronic commerce since always. Business to business electronic commerce has been slower to develop than its counterpart, i.e. business to consumer E-commerce. However business to business e-commerce is starting to attract an increased interest, by showing a significant business value in terms of potential. Against this background, the slow development of B2B e-commerce has been linked to regulatory and economic reasons. In order to deal with such stumbling blocks, the paper suggests a shift towards an open platform that is aimed at facilitating transactions and interactions among businesses through a continuous problem-solving process in which trust and value is co-created by producers and customers through relational contracting.
\end{abstract}

\section{Introduction}

The internet has produced a forward-looking shift in the way we communicate, think and run economic activities around the globe. The Internet has allowed us to build a virtual place in which items are traded as well as orders and payments are made. As a result, the spatial and temporal concept of commercial interchanges is still evolving. The wine industry is a case in point. Indeed, the industry has attempted to address the multifaceted challenges posed by electronic commerce since always. Many business experiences have been accumulated in selling products directly to consumers, i.e. business to consumer E-commerce. Conversely, business to business commerce has been slower to develop than its counterpart.

The slow development of B2B e-commerce - in particular in relation to small and medium sized businesses - has been linked to regulatory and economic reasons. Through an investigation of the related stumbling blocks, the paper aims at exploring the implications of an intermediary-oriented e-marketplace that facilitates transactions and interactions in a problem-solving process in which trust and value is co-created by producers and customers through a relational contracting. This is analysed in the framework of further developing emerging trading opportunities for small and medium sized wine producers.

The structure of the paper is threefold. Part I examines what the main aspects of e-marketplaces and their role within the contest of ICT. Part II recognises a need of rethinking the role of e-marketplace as intermediary in facilitating and building trust among businesses. Part III explores a (preliminary) model of relational intermediaryoriented e-marketplace. By filling the gap generated by the distance and the resulting lack of personal interaction among businesses, this model may represent a consistent opportunity to build trust and create value through e-marketplaces.

\section{B2B e-commerce in wine business: present and past}

ICT has changed the way we do trade at all levels, including Business to Consumers (B2C) and Business to Business (B2B) transactions [1]. A relatively vast body of literature has investigated the role played by the e-commerce in the agri-food supply chain, thus enabling new commercial and trading patterns in the agri-food sector [2]. The potential of ICT in B2B e-commerce has been widely recognised in the agri-food sector; indeed, the revolution in ICT has generated an innovating process that is far from being unwind [3]. While B2B e-commerce is starting to attract an increased interest - by showing a significant business value in terms of potential - its slow development and diffusion requires a renovated attention in (re-) considering the stumbling blocks that are linked to both regulatory and economic reasons [4].

The wine industry is a case in point. Indeed, the industry has attempted to address the multifaceted challenges posed by e-commerce since always. The wine sector has been deeply involved with high expectations regarding the potential growth of the sector as results of adopting ICT. Producers had made many attempts in adjusting their habits as well as increasing their confidence in the digital instrument, by taking into consideration possible advantages and disadvantages in terms of legal and economic factors. 
In this framework, the development of e-marketplace has been considered in the literature as a corner-stone in the global process of improving ICT for building more efficient business models [5]. E-marketplaces have played (and are continuing to play) an important role in boosting the e-business world.

In the scientific literature, several scholars have devoted huge efforts in exploring definitions for electronic marketplace [6]. This consistently reflects the evolution that has involved e-marketplaces over the years [7]. By focusing on their unique characteristic of being able to bring multiple buyers and sellers together in one virtual market space, the present paper consider an e-marketplace as an open platforms that is aimed at facilitating transactions and interactions among businesses [8]. In doing this, e-marketplace may enable both economy of scale and economy of scope.

\subsection{E-commerce and its (legal) geographical boundaries}

At first sight e-marketplace - and generally speaking, the entire e-commerce sector - may give the perception of eliminating the usual geographic boundaries. Indeed, it seems that the Internet may be considered as a unique and exceptional unicum of buyers and sellers that act in the same and infinite space. One of the consequences of this representation is the idea associated to the possible elimination of intermediaries, thus resulting in cutting costs - particularly for small and medium-sized businesses that may concretely access potentially unlimited markets with a higher profit margin.

The real world, however, suggests something different. When dealing with e-commerce, geographical boundaries exist. A real product, in our case wine, is physically shipped from one country to another one after finalising the purchase over the Internet. Therefore, the online transaction will be subject to all the possible issues that usually affect international trades. This implies that import and export regulations as well as food laws have to be considered. Consequently, the regulatory framework assumes a main relevance to determine the expansion and the success of the wine e-commerce.

Before the discussion moves to the regulatory issues, one preliminary aspect is worth to be further explored. The wine is a product to which not only import/export regulation applies, but also a (legal) awareness has been paid as a result of being destined to human consumption. Therefore, the regulatory burden rises considerably if compared to other items, such as clothes for example, due to the health issues of drinking wine. The health concerns are considered both in terms of consequent diseases and direct [9], and indirect effects [10].

The complex and indissoluble twine of legislations has been listed in relation to different areas, accordingly to the relevant literature [11]. Examples are specifically provided in relation to the EU legislation on wine export from nonEU countries to EU countries.

a. Taxation systems. It should be taken into consideration when deciding to export wine, in particular different rules regulating the tax system may considerably differ from country to country. In Europe, for example, the VAT rate can change among Member States as a uniform VAT system does not exist [12];

b. Tariffs. These include a wide range of expenses that need to be managed when dealing with certain countries [13]. In Europe, a specific database, called the 'TARIC', is provided in order to allow interested companies to find out the amount of the tariffs [14];

c. Licensing. In order to export products in certain countries, producers should be aware of the existing regulation about licensing, i.e. a specific licence may be required to import wine [15];

d. Labelling. While the content of the labels may change over time, a producer that is willing to export to different countries should be confident with labelling legislation, thus considering different labels in compliance with the legal provisions. This part includes also Geographical Indications and other certification schemes, such as the organic certification process [16]. The EU regulatory framework is particularly stringent, i.e. Regulation $1169 / 2011$ in combination with the implementing rules provided under the Regulation 607/2009 [17];

e. Controls. As previously mentioned, wine represents a good that could affect the consumer health; therefore, countries may establish different control system considering the fact that substances might be admitted in one country and not in others. In Europe, the Commission Regulation 555/2008 lays down implementing rules regarding, inter alia, certification and analysis report requirements [18]. Furthermore, Regulation 606/2009 specifies the oenological practices authorized in the EU [19].

\subsection{Stumbling blocks}

The wine sector has been traditionally influenced to a great extent by a number of long-established trading patterns and common habits in building business relationship. In particular, intermediaries have played an essential role in aggregating needs of buyers and producers, thus consolidating long-term relationship, personal commitment and trust among them [20]. This clashes with the risk and uncertainty involved in an environment in which all these patterns are less perceivable [21]. As illustrated in the literature, such patterns result in a higher perceived information asymmetry among parties in an e-business in which the transactions are carried out in an environment with only virtual relations - that is, an e-environment. More easily, it may give room for opportunistic behavior. Information asymmetry affects all the points that characterise the electronic transaction: product, buyer-and-seller relationships and market environment [22].

In the literature, three key areas of concern have been identified in taking the decision to adopt an electronic marketplace: (1) market blocks; (2) organizational blocks; and, (3) socio-cultural blocks [23]. Such areas of concern represent stumbling blocks in the choice of small and medium-sized producers of using an electronic marketplace in their own business to business relationships. Such blocks has been further strengthen by a generalized lack of knowledge and skills in adopting an ICT tool, while the information asymmetry increases the resulting perceived risk [24]. 


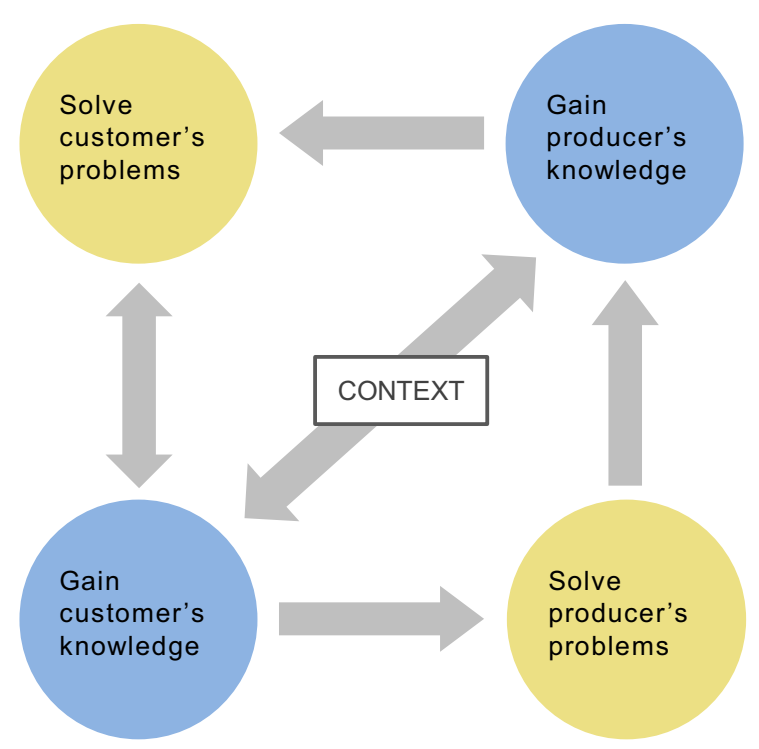

Figure 1. Intermediary reinforcing cycle [28].

\section{Rethinking the role of intermediaries}

While ICT has had the ambition of carrying out a disintermediation of (nearly) all the economic sectors, they are boosting intermediation in a different form that does not match with traditional categories [25]. An intermediary is valuable in consideration of its beingin-between nature [26]. The proposal, here, consists in a call for an intermediary oriented e-marketplace. Intermediaries are best situated to aggregate the needs of different and eventually heterogeneous groups of customers in purchasing products. Conversely, producers have a range of needs that include negotiation, transaction settling, pre- and post-sale assistance, advertising and logistics. An intermediary may provide an augmented value for producers by bundling such needs. This results in an intermediary that gathers knowledge while serving the interrelated needs of customers and producers [27]. Indeed, the intermediary-oriented e-marketplace becomes the best-informed player in business to business e-relationship. Being able to solve customer problems, it will be able to solve producer problems.

As illustrated in Fig. 1, this creates a mutually reinforcing cycle in which intermediaries give context to the information gained. This creates a competence based framework in which intermediaries may be considered as facilitator and 'complementors' to the producer [29]. Such a cycle will continue its problem-solving process by following the evolutionary movement of ICT. In this scenario, an e-marketplace acts as an intermediary in facilitating electronic transactions and enhancing the intangible asset of trust among businesses [30]. Indeed, such an intermediary-oriented e-marketplace may reduce uncertainties and risks through information sharing and problem solving; thus, limiting information asymmetry and the resulting transaction costs.

\section{Towards a relational e-marketplace: A way to enhance value (co-)creation?}

A shift is suggested towards an open platform that is aimed at facilitating transactions and interactions among

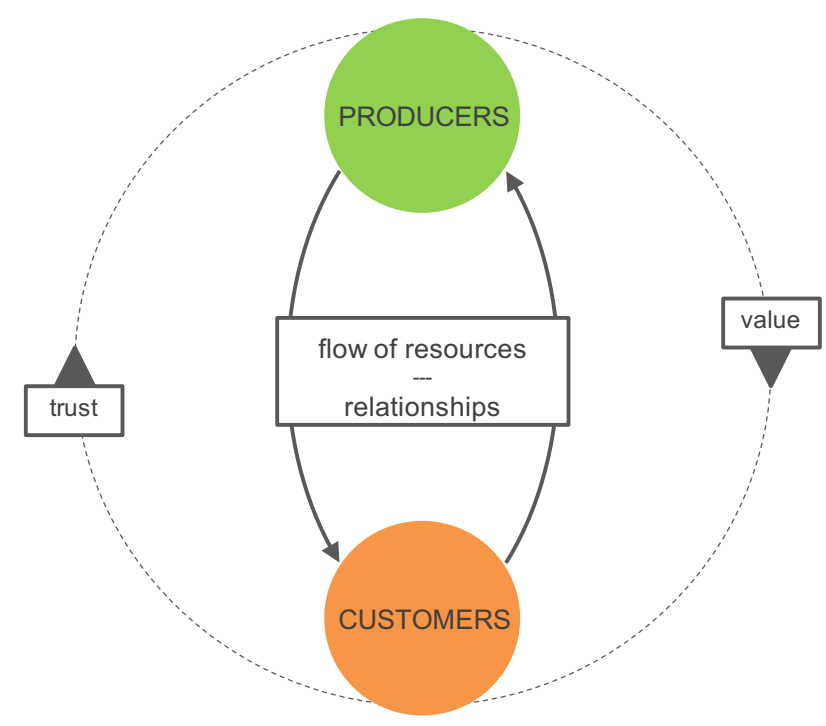

Figure 2. Relational intermediary-oriented model.

businesses through a continuous problem-solving process in which trust and value is co-created by producers and customers through a relational contracting - as illustrated in Fig. 2.

While a comprehensive model around the many implications that are involved is too pretentious for this paper, the aim, here, is to contribute to the current discussion by building a common (yet preliminary) understanding of a relational intermediary-oriented model of e-marketplace. In order to discuss the resulting implications, this section will firstly investigate the role played by relational contracting in the model and, secondly, the conceptual framework of value co-creation within which long-term relationships and trust are built.

Relational contracting usually emerges under conditions of uncertainty and complexity, in which a relational contract relies on the trust between parties that enter a contractual relationship in order to work together for a mutual benefit outcome [31]. Such contractual arrangement is particularly common in business contexts, where flexible relational contracts are essential [32]. An extensive body of literature exists in the United States on the introduction of a degree of flexibility in contracts and the use of informal sanction to maintain cooperation among business actors [33]. Based on a qualitative research on business executives, Macaulay found that commercial long-term relationship rarely involves, or are based on, formal written contracts [34]. The primary motivation is performing contractual obligations consists in preserving reputation of being good business partners on which others may count for future deals.

The relational approach maintains that the contract should be considered as embedded in a specific socioeconomic context. In such perspective, contracting does not occur in a 'social vacuum', but in a 'relational web' [35]. The temporal dimension of the relationship plays a key role in such understanding [36]. Accordingly to a commentator, "emphasis on discrete transactions abstracted from the ongoing relationships in which they occur distorts the character of the transactions and of the relationships themselves' [37]. The introduction of a relational dimension into the contractual mechanism 
has been widely discussed in academia (particularly in the United States) during the last fifty years; indeed, it produced extensive scientific research in the law area and economics studies. Arguably, the understanding of a relational dimension resulted in multiple changes in the way in which legal scholars deal with contractual arrangements, by contributed to some extent to adjust the classical contractual perspective [38]. Among others, the empirical studies and, more recently, the law and economics perspective have been set as a response to the changes in the understanding of law as a scientific area [39].

It is essential to note one of the aspects that plays a key role in such an approach: the contract should be understood as a relational event affected by external influences and internal values that produce ongoing adjustments and assure its progression [40]. Indeed, the value of solidarity and reciprocity play a key role in a relational approach, also representing a reaction to the individualism involved in classical contracting [41].

In order to build long-lasting relationships and trust among producers and customers involved in electronic transition, both parties need to interact in the value generation process. Such a long-lasting relationship and trust are created through customer retention [42]. This is achieved by 'accessing customers in the target market, continuing customer dialogues, and choosing efficient ways in treating them such as personalized treatment' [43]. However, the lack of direct interaction in e-commerce is considered as an element that may undermine the real possibility of converting customer retention in a long-term relationship [44].

In relationship building, a number of interactive activities has been identified in literature: (1) transactional interaction, in which the focus is on the transaction as a central economic activity and in particular the time frame is considered the key aspect; (2) value-added interaction, in which customers are attracted by a relational adjustment and amendment of the products to the needs of the customers; and, (3) collaborative interaction, in which customers and producers are committed in a close collaboration for mutual long-term benefits [45]. While substantial differences exist among the activities, these processes are considered as related parts that contribute to relationship building [46].

Customer and producer are closely intertwined during the interaction process. In this line, "co-creation is regarded as a function of interaction and value creation as direct interactions between value-creating resources and a beneficiary' [47]. According to the literature, value creation process need to be considered through an interactive perspective under which is possible to investigate how the contribution of different resources are integrated in the process [48]. By way of interaction, both customers and producers share (and gain new) information, receive advice and build trust [49].

Within this framework, the literature has identified interrelated components as useful for a business to build a value co-creation capability: producers need to listen to and engage with their customers, thus becoming able to respond externally through the provision of tools for value co-creation and internally by establishing investment efforts in co-creation structures [50]. Such components are complementary in relationship building and value co-creation [51].

\section{Conclusion}

While e-marketplaces are considered a corner-stone in developing more efficient business models and boosting the e-business world, a number of stumbling blocks - both economic and regulatory - are identified as reasons of its slow development in business to business relationships. Against this background, the wine industry is a case in point. At first sight e-marketplace may give the perception of eliminating the usual geographic boundaries. However, such an e-environment and the relating lack of personal interaction increase the risks and uncertainty involved. In this line, information asymmetries between producers and customers have been recognised as affecting all the point in the electronic transaction.

A shift has been suggested towards an open platform that facilitates transactions and interactions among businesses through a continuous problem-solving process in which trust and value is co-created by producers and customers through a relational contracting. In a relational intermediary-oriented model, e-marketplace acts as an intermediary in facilitating electronic transactions and enhancing the intangible asset of trust among businesses. Such a model may reduce uncertainties and risks through information sharing and problem solving; thus, limiting information asymmetry and the resulting transaction costs.

\section{References}

[1] See, among others, Z. Andreopoulou and others, Typology for e-business activities in the agricultural sector, International Journal of Business Information Systems, 3 (2008)

[2] For a comprehensive overview, see Y. Zeng and others, E-commerce in Agri-food Sector: A Systematic Literature Review, The International Food and Agribusiness Management Review (2017). A fascinating contribution has been recently provided by the research findings achieved by the EU Project 'E-Trust - Building trust for quality assurance in emerging markets for food chains', funded under the EU Sixth Framework Programme. See M. Fritz and others, Commercio elettronico per la dinamica delle catene agro-alimentari internazionali: un'analisi del potenziale, Working Paper DEIAgraWP-08-006

[3] See, inter alia, M. Fritz, T. Hausen, G. Schiefer, Developments and Development Directions of Electronic Trade Platforms in US and European AgriFood Markets: Impact on Sector Organization, International Food and Agribusiness Management Review, 7 (2004)

[4] Among others, see J. Henderson and others, Adoption of Internet strategies by agribusiness firm, International Food and Agribusiness Management Review, 8 (2005); and, N. Leroux, S. Wortman, D. Mathias, Dominant factors impacting the development of business-to-business (B2B) e-commerce in agriculture, International Food and Agribusiness Management Review, 4 (2001)

[5] See M. Canavari, M. Fritz, G. Schiefer, Food Supply Networks. Trust and E-business (CABI, Wallingford, 2016). See also T. Skjøtt-Larsen, H. Kotzab, M. Grieger, Electronic marketplaces and supply chain relationships, Industrial Marketing Management, 32 (2003) 
[6] See, among other, T.Y. Eng, The role of e-marketplaces in supply chain management, Industrial Marketing Management, 33 (2004); M. Grieger, Electronic marketplaces: a literature review and a call for supply chain management research, European Journal of Operational Research, 144 (2003); M. Grieger, An empirical study of business process across Internet-based electronic marketplaces. A supply-chain management perspective, Business Process Management Journal, 10 (2004); C. Standing, S. Standing, The relationship between electronic marketplace strategy and structure. In: C. Standing, (ed.), Electronic Markets - Benefits, Costs and Risks (Palgrave Macmillan, Basingstoke, 2009)

[7] See M. Canavari, M. Fritz, G. Schiefer, Food Supply Networks. Trust and E-business (CABI, Wallingford, 2016)

[8] See, among others, H.H. Holzmuller, J. Schluchter, Delphy studies about the future of B2B marketplaces in Germany, Electronic Commerce Research and Applications, 1 (2002)

[9] An example regarding direct effects may be linked to an improper content of the product that can cause side effects to the consumers, such as intoxication

[10] An example regarding the indirect effects is the addiction that might arise from an exaggerate consumption of wine

[11] The identification of different areas with subdivisions is very well presented in the contribution given by S.A. Hincliffe, Trademarks, GIs, and Commercial Aspects of Wine Distribution Agreements, Journal of Food Law \& Policy, 10 (2014)

[12] A complete list of VAT rates applicable can be found at http://ec.europa. eu/taxation_customs/resources/documents/ taxation/vat/how_vat_works/rates/vat_ rates_en.pdf . Accessed 10 April 2017

[13] An example is represented by Europe

[14] For more information, see the database at http:// ec.europa.eu/taxation_customs/dds2/ taric/taric_consultation.jsp. Accessed 10 April 2017

[15] A number of specific examples exists that are applicable to EU Member States. It is also worth mentioning the ongoing debate in the United States regarding the fact whether it is legal or not to sell wine, over the Internet, without a licence to the States where a licence is required. See J.A. Tanford, E-commerce in Wine, Journal of Law, Economics and Policy, 3 (2007); and, V. H. Jones, Put a Cork in it: the Use of H.R. 1161 to end Direct Wine Shipping throughout the States once and for All, Journal of Food Law \& Policy, 8 (2012)

[16] See S.A. Hinchliffe, Trademarks, GIs, and Commercial Aspects of Wine Distribution Agreements, Journal of Food Law and Policy, 10 (2014)

[17] See Regulation (EU) No 1169/2011 of the European Parliament and of the Council of 25 October 2011 on the provision of food information to consumers, amending Regulations (EC) No 1924/2006 and (EC) No $1925 / 2006$ of the European Parliament and of the Council, and repealing Commission Directive 87/250/EEC, Council Directive 90/496/EEC, Commission Directive 1999/10/EC, Directive 2000/13/EC of the European Parliament and of the Council, Commission Directives 2002/67/EC and 2008/5/EC and Commission Regulation (EC) No 608/2004, OJ L 304 [2011]; and, Commission Regulation (EC) No 606/2009 of 10 July 2009 laying down certain detailed rules for implementing Council Regulation (EC) No 479/2008 as regards the categories of grapevine products, oenological practices and the applicable restrictions, OJ L 193 [2009]

[18] See article 41, Commission Regulation (EC) No 555/2008 of 27 June 2008 laying down detailed rules for implementing Council Regulation (EC) No $479 / 2008$ on the common organisation of the market in wine as regards support programmes, trade with third countries, production potential and on controls in the wine sector, OJ L 170 [2008]

[19] See Commission Regulation (EC) No 606/2009 of 10 July 2009 laying down certain detailed rules for implementing Council Regulation (EC) No 479/2008 as regards the categories of grapevine products, oenological practices and the applicable restrictions, OJ L 193 [2009]

[20] Among others, see E. Pignatti and others, Nuove dinamiche nel commercio dei prodotti agroalimentari: resistenze all'adozione dell'e-commerce nelle relazioni B2B, Working Paper DEIAgraWP-08-005 (2008)

[21] See M. Fritz, M. Canavari, Management of perceived e-business risks in food-supply networks: e-trust as prerequisite for supply-chain system innovation, Agribusiness, 24 (2008)

[22] See M. Canavari, M. Fritz, G. Schiefer, Food Supply Networks. Trust and E-business (CABI, Wallingford, 2016)

[23] See, inter alia, E. Pignatti and others, Nuove dinamiche nel commercio dei prodotti agroalimentari: resistenze all'adozione dell'e-commerce nelle relazioni B2B, Working Paper DEIAgraWP-08-005 (2008)

[24] See M. Canavari, M. Fritz, G. Schiefer, Food Supply Networks. Trust and E-business (CABI, Wallingford, 2016)

[25] See P. Anderson, E. Anderson, The New E-Commerce Intermediaries, MIT Sloan Management Review (Summer, 2002)

[26] Compare with S. Wang, N. Archer, Business-tobusiness collaboration through electronic marketplaces: an exploratory study, Journal of Purchasing \& Supply Management, 13 (2007)

[27] Among others, see M. Kourgiantakis, E. Petrakis, Modelling B2B E-marketplace: the role of intermediaries, Work supported by the Greek Ministry of Development, General Secretariat of Research and Technology under the Operational Programme Competitiveness (PENED, 2007)

[28] This figure is based on the research carried out in P. Anderson, E. Anderson, The New E-Commerce Intermediaries, MIT Sloan Management Review (Summer, 2002) 
[29] See P. Anderson, E. Anderson, The New E-Commerce Intermediaries, MIT Sloan Management Review (Summer, 2002)

[30] Compare with M. Canavari and others, Prioritizing trust factors in an agrifood $B 2 B$ e-commerce environment. In: G. Schiefer, M. Fritz, U. Rickert, (eds), Trust and Risk in Business Networks (University of Bonn - ILB Press, Bonn, 2006)

[31] For a comprehensive discussion of relational contract, see, among others, the topical research in C.J. Goetz, R.E. Scott, Enforcing Promises: An Examination of the Basis of Contract, Yale Law Journal, 89 (1980); C.J. Goetz, R.E. Scott, Principles of Relational Contracts, Virginia Law Review, 67 (1961); and, I.R. Macneil, Relational Contract: What We Do and Do Not Know, Wisconsin Law Review (1985)

[32] Among others, see J.M. Feinman, Relational Contract Theory in Context, Northwestern University Law Review, 94 (2000); and, M. Diathesopoulos, Relational contract theory and management contracts: A paradigm for the application of the Theory of the Norms, MPRA Paper No. 24028 (2010)

[33] On this, see S.Baker, A. Choi, Contract's role in relational contract, Virginia Law Review, 101 (2015). For example, see R. Ellickson, Order Without Law: How Neighbors Settle Disputes (Havard University Press, Cambridge, 1991); L. Bernstein, Opting Out of the Legal System: Extralegal Contractual Relations in the Diamond Industry, Journal of Legal Studies, 21 (1992); L. Bernstein, Private Commercial Law in the Cotton Industry: Creating Cooperation Through Rules, Norms, and Institutions, Michigan Law Review, 99 (2001)

[34] See S. Macaulay, Non-Contractual Relations in Business: A Preliminary Study, American Sociological Review, 28 (1963)

[35] See I. Macneil, Values in Contracts: Internal and External, Northwestern University Law Review, 78 (1983)

[36] A fascinating analysis has been carried out in the Italian literature, see particularly M. Granieri, Il tempo e il contratto. Itinerario storico-comparativo sui contratti di durata (Giuffrè Editore, Milano, 2007)

[37] See G.A.G. Gottlieb, Relationism: Legal Theory for a Relational Society, University of Chicago Law Review, 50 (1983)

[38] Among others, see E. Mertz, Afterword: Tapping the Promise of Relational Contract Theory Real Legal Language and a New Legal Realism, Northwestern University Law Review 94 (1999)
[39] A true pioneer may be considered K.N. Llewellyin which in 1925 argued that law is "as a thing in a flux" and its development depends on "non-legal- factors" See K.N. Llewellyin, The effects of legal institution upon economics, American Economic Review, 14 (1925). For a comprehensive analysis, see C. Farelli, L'eredità del realismo giuridico americano, Materiali per una storia della cultura giuridica, 1 (2006). Also, compare with M. Granieri, Il tempo e il contratto. Itinerario storico-comparativo sui contratti di durata (Giuffrè Editore, Milano, 2007)

[40] See I.R. Macneil, The Many Futures of Contracts, Southern California Law Review, 47 (1974)

[41] See M. Granieri, Il tempo e il contratto. Itinerario storico-comparativo sui contratti di durata (Giuffrè Editore, Milano, 2007)

[42] Mutatis mutandis, it is interesting to compare with the research findings in J. Riegelsberger, A. Sasse, Trustbuilders and trustbusters. The role of trust cues in interfaces to e-commerce applications, Proceedings of the 1st IFIP Conference on towards the e-Society: ecommerce, e-business, e-government: 17-30. IFIP Conference, 3-5 October 2001, Zurich (Switzerland)

[43] See G. Bhalla, Collaboration and Co-creation. New Platforms for Marketing and Innovation (Springer, Heidelberg, 2011)

[44] See G. Bhalla, Collaboration and Co-creation. New Platforms for Marketing and Innovation (Springer, Heidelberg, 2011)

[45] See M.D. Hutt, T.W. Speh, Business Marketing Management: B2B (Cengage, Boston, 2013)

[46] See G. Bhalla, Collaboration and Co-creation. New Platforms for Marketing and Innovation (Springer, Heidelberg, 2011)

[47] See L. Chen, J. Marsden, Z. Zhang, Theory and Analysis of Company-Sponsored Value Co-Creation, Journal of Management Information Systems, 29 (2012)

[48] See, among others, S.L. Vargo, R.F. Lusch, Evolving to a New Dominant Logic for Marketing, Journal of Marketing, 68 (2004)

[49] See, among others, A. Walter, T. Ritter, The influence of adaptations, trust, and commitment on valuecreating functions of customer relationships, Journal of Business \& Industrial Marketing, 18 (2003)

[50] See G. Bhalla, Collaboration and Co-creation. New Platforms for Marketing and Innovation (Springer, Heidelberg, 2011)

[51] Mutatis mutandis, see M. Fritz, E-commerce partnering due diligence: a methodology for trust in e-commerce in food networks, Acta Agriculturae Scandinavica, Section C - Food Economics, 4 (2007) 